\title{
Hubungan antara Penggunaan Helm Standar dengan Insidensi Fraktur Tulang Muka dan Tulang Kepala
}

\author{
Mahfud $^{1}$ \\ ${ }^{1}$ Sekolah Tinggi IImu Kesehatan Alma Ata Yogyakarta \\ Jalan Ringroad Barat Daya No 1 Tamantirto, Kasihan, Bantul Yogyakarta
}

\begin{abstract}
Abstrak
Kecelakaan lalu-lintas menyebabkan 6\% morbiditas dan 3,5\% mortalitas dari populasi. Penggunaan helm standar yang paling baik dapat menurunkan resiko kematian sampai 30\%,kecelakaan akibat benturan pada kepala merupakan penyebab utama kematian pada kecelakaan kendaraan bermotor. Penelitian non experimental dengan disain retrospektif ini bertujuan mengetahui hubungan antara penggunaan helm standar dengan insidensi fraktur tulang muka dan tulang kepala di RSUD Sleman. Hasil penelitian ini menunjukan bahwa Helm standar terbukti mengurangi resiko fraktur tulang muka dan tulang kepala pada kecelakaan kendaraan bermotor roda dua terbukti dari 12 kasus kecelakaan untuk pengguna helm standar 66,66\% tidak mengalami fraktur tulang muka dan tulang kepala. Simpulan dari enelitian ini adalah ada hubungan antara penggunaan helm standar dengan insidensi fraktur tulang muka dan tulang kepala.
\end{abstract}

Kata Kunci: hipertensi, usia lanjut

Info Artikel:

Artikel dikirim pada 02 September 2013

Artikel diterima pada 02 September 2013

\section{PENDAHULUAN}

Di Indonesia, 10-20\% penderita yang masuk rumah sakit rata-rata adalah korban kecelakaan lalu-lintas. Dalam tahun 2000, kematian karena kecelakaan lalu-lintas kurang dari 7000 , sementara tahun 2002 angka kematian mencapai 12.000 , suatu kenaikan yang memprihatinkan [1].

Kecelakaan lalu-lintas menyebabkan 6\% morbiditas dan 3,5\% mortalitas dari populasi. Dari $10 \%$ kapasitas tempat tidur di RS yang diisi korban kecelakaan lalu-lintas dan sekitar $60 \%$ kematian adalah karena perlukaan kepala, sementara kerugian materi yang diakibatkan kurang-lebih $1 \%$ dari GNP [1]. Data kecelakaan lalu-lintas di Indonesia tahun 2000-2005 terdapat kenaikan angka kecelakaan sebesar $14,5 \%$ setiap tahunnya. Di Indonesia setiap harinya terdapat orang meninggal akibat kecelakaan lalu-lintas [1].

Di Sleman data penderita karena kecelakaan lalu lintas tahun 2006-2007 yang masuk RSUD Sleman adalah $2-5 \%$ dari data rekamedis RSUD Sleman. Rambu-rambu lalu lintas dan termasuk juga helm standar bagi pengendara sepeda motor hanyalah sebagai instrumen untuk mengingatkan bahwa siapa pun yang berada di atas jalan raya terikat pada kepentingan umum atau kepentingan bersama. Setiap pengendara kendaraan bermotor, roda empat, maupun roda dua, juga akan diuji kemampuannya dalam berdemokrasi di arena publik yang disebut jalan raya itu. Semakin jelas bahwa jalan raya adalah milik umum atau milik bersama, sementara soal helm standar bagi pengendara sepeda motor adalah kelanjutan tafsir atas semua kepentingan orang terhadap jalan raya.

Besdasarkan studi pendahuluan tanggal 8-10 september 2007 data pengendara sepeda motor roda dua yang mengalami kecelakaan lalu lintas dan mengalami fraktur tulang muka dan kepala yang berobat di UGD RSUD Sleman kurang lebih 10-15 setiap bulannya. Fraktur tulang muka adalah diskontinuitas dar jaringan tulang muka (patah tulang) yang biasanya disebabkan oleh adanya kecelakaan yang timbul secara mendasar. [2].

Kerusakan pada kepala paling banyak dijumpai sebagai penyebab kematian dibanding dengan bagian anggota tubuh yang lain[3]. Dari polling Pusat Studi Hukum (PSH) Fakultas Hukum Ull pada bulan Maret 
2002 lalu, terbukti bahwa 71,7 persen (210 orang) dari 293 responden yang memiliki sepeda motor di Yogyakarta telah mengerti tentang helm standar. Akan tetatapi, 40,5 persen (83 persen) dari 293 responden belum menggunakan helm standar karena harganya yang mahal. Inilah titik keresahan masyarakat yang harus serius diperhatikan oleh pemerintah. [4].

Dengan demikian kewajiban memakai helm standar memang sangat dianjurkan sesuai dengan UU no 14/ 1992, Peraturan Pemerintah no 44/1993 dan dalam keputusan menteri perhubungan no $72 / 1993$. Penggunaan helm standar yang baik dapat menurunkan resiko kematian sampai $30 \%$, kecelakaan akibat benturan pada kepala merupakan penyebab utama kematian pada kecelakaan kendaraan bermotor [5].

Dari semua pasien $73 \%$ penderita fraktur adalah laki-laki dan wanita hanya $27 \%$ [6]. Untuk mengetahui letak fraktur diadakan rongten foto kepala dibuat dengan proyesi antero posterior, lateral dan waters [7].

Maka dengan ini helm merupakan suatu alat keselamatan atau pelindung yang efektif bagi pengendara bermotor, saat ini banyak helm yang dijual dipasaran yang sangat menarik dan warna yang beragam akan tetapi tidak semua helm dapat benarbenar melindungi kepala. Helm standar yang benar adalah melindungi bagian kepala belakang,samping, serta depan muka [8].

\section{BAHAN DAN METODE}

Penelitian ini merupakan penelitian deskriptif jenis restrospektif dilakukan dari bulan November sampai dengan bulan Desember. Objek dari penelitian ini adalah fraktur tulang muka dan tulang kepala yang terjadi pada kecelakaan kendaraan bermotor dengan mengacu pada helm yang dikenakan (tidak mengunakan helm, menggunakan helm tapi tidak standar atau menggunakan helm standar). Instrument yang digunakan dalam penelitian ini adalah kuesioner.

\section{HASIL DAN BAHASAN}

Tabel 1. Distribusi Frekwensi Responden dengan Fraktur Tulang Muka dan Kepala di RSUD Sleman

\begin{tabular}{lll}
\hline Karakteristik responden & Frekwensi & Posentase \\
\hline a. SD & 3 & $5,67 \%$ \\
b.SMP & 6 & $11,53 \%$ \\
c.SMU & 27 & $51,72 \%$ \\
d.DIII/S1 & 16 & $30,76 \%$ \\
\hline
\end{tabular}

\begin{tabular}{lll}
\hline Pekerjaan & & \\
\hline a.Tani & 9 & $17,30 \%$ \\
b.PNS & 25 & $48,07 \%$ \\
c.Wiraswasta & 18 & $34,61 \%$ \\
\hline Umur & & \\
\hline a. $10-20^{\text {th }}$ & 17 & $32,89 \%$ \\
b. $21-30^{\text {th }}$ & 21 & $40,36 \%$ \\
c. $31-40^{\text {th }}$ & 10 & $19,63 \%$ \\
d. $41-50^{\text {th }}$ & 2 & $3,84 \%$ \\
e. $>51$ th & 2 & $3,84 \%$ \\
\hline
\end{tabular}

Sumber: Data Primer

Tabel 2.Distribusi Frekwensi Responden yang Mengalami Kecelakaan Kendaraan Roda Dua dengan Fraktur Tulang Muka dan Kepala Berdasarkan Jenis Helm Di Rsud Sleman

\begin{tabular}{lll}
\hline \multicolumn{1}{c}{ Penggunaan helm } & Frekwensi & Prosentase \\
\hline Tanpa Helm & 12 & $23,07 \%$ \\
Helm tidak standar & 28 & $53,84 \%$ \\
Helm Standar & 12 & $23,07 \%$ \\
\hline Jumlah & 52 & $100 \%$
\end{tabular}

Sumber: Data Primer

Tabel 3. Persentase Data Kendaraan Bermotor yang Mengalami Kecelakaan dengan Fraktur Tulang Muka,Fraktur Tulang Kepala, Tanpa Fraktur November -Desember Di RSUD Sleman

\begin{tabular}{lll}
\hline \multicolumn{1}{c}{ Jenis Fraktur } & Frekwensi & Prosentase \\
\hline Fraktur tulang Muka & 23 & $44,23 \%$ \\
Fraktur tulang kepala & 10 & $19,23 \%$ \\
Tanpa fraktur & 19 & $36,53 \%$ \\
\hline Jumlah & 52 & $100 \%$ \\
\hline
\end{tabular}

Sumber: Data Primer

Tabel 4.Data Kendaraan Bermotor Roda Dua yang Mengalami Kecelakaan Bulan November-Desember Di RSUD Sleman

\begin{tabular}{llll}
\hline Pengguna Helm & $\begin{array}{c}\text { Tanpa } \\
\text { Fraktur }\end{array}$ & $\begin{array}{l}\text { Dengan } \\
\text { Fraktur }\end{array}$ & Jumlah \\
\hline Tanpa Helm & 4 & 8 & 12 \\
HelmTidak Standar & 7 & 21 & 28 \\
Helm Standar & 8 & 4 & 12 \\
\hline Jumlah & 19 & 33 & 52 \\
\hline
\end{tabular}

Sumber: Data Primer

Tabel 5. Presentasi Data Kendaraan Bermotor yang Mengalami Kecelakaan dari Seluruh Kejadian Pada Bulan November-Desember Di RSUD Sleman

\begin{tabular}{llll}
\hline Pengguna Helm & $\begin{array}{c}\text { Tanpa } \\
\text { Fraktur }\end{array}$ & $\begin{array}{c}\text { Dengan } \\
\text { Fraktur }\end{array}$ & Jumlah \\
\hline Tanpa Helm & $7,3 \%$ & $15 \%$ & $22,3 \%$ \\
HelmTidakStandar & $13,1 \%$ & $40 \%$ & $53,1 \%$ \\
Helm Standar & $15,3 \%$ & $9,6 \%$ & $24,4 \%$ \\
\hline Jumlah & $35,4 \%$ & $64,6 \%$ & $100 \%$ \\
\hline Sumber: Data Primer & &
\end{tabular}




\section{Uji Statistik}

Korelasi Phi ( ${ }^{f}$ ) digunakan untuk menguji hubungan/ korelasi antara dua variable dalam bentuk skala nominal diskrit dan nominal diskrit [9]. Adapun formula korelasi Phi $\left({ }^{f}\right)$ adalah:

$$
\phi=\frac{\mathrm{BC}-\mathrm{AD}}{\sqrt{(\mathrm{A}+\mathrm{B})(\mathrm{C}+\mathrm{D})(\mathrm{A}+\mathrm{C})(\mathrm{B}+\mathrm{D})}}
$$

Tabel 6. Tabel Phi Pengendara Kendaraan Bermotor Roda Dua yang Memakai Helm yang Mengalami Kecelakaan Pada Bulan November-Desember

\begin{tabular}{llll}
\hline Penggunan Helm & $\begin{array}{l}\text { Tanpa } \\
\text { Fraktur }\end{array}$ & $\begin{array}{l}\text { Dengan } \\
\text { Fraktur }\end{array}$ & Jumlah \\
\hline Dengan Helm & 15 & 25 & 40 \\
Tanpa Helm & 4 & 8 & 12 \\
\hline
\end{tabular}

Sumber: Data primer.

$$
\begin{aligned}
\phi & =\frac{\mathrm{BC}-\mathrm{AD}}{\sqrt{(\mathrm{A}+\mathrm{B})(\mathrm{C}+\mathrm{D})(\mathrm{A}+\mathrm{C})(\mathrm{B}+\mathrm{D})}} \\
\phi & =\frac{100-120}{\sqrt{(40)(12)(19)(33)}} \\
& =-0,036
\end{aligned}
$$

Tabel 7. Tabel Phi Pengendara Kendaraan Bermotor Roda Dua yang Memakai Helm Standar dan Tidak Standar yang MengalamiKecelakaan Lalu Lintas Bulan November-Desember

\begin{tabular}{llll}
\hline Penggunaan Helm & $\begin{array}{c}\text { Tanpa } \\
\text { fraktur }\end{array}$ & $\begin{array}{l}\text { Dengan } \\
\text { Fraktur }\end{array}$ & Jumlah \\
\hline Helm Standar & 8 & 4 & 12 \\
Helm tdk standar & 7 & 21 & 28 \\
\hline
\end{tabular}

Sumber: Data Primer

$$
\begin{aligned}
\phi & =\frac{\mathrm{BC}-\mathrm{AD}}{\sqrt{(\mathrm{A}+\mathrm{B})(\mathrm{C}+\mathrm{D})(\mathrm{A}+\mathrm{C})(\mathrm{B}+\mathrm{D})}} \\
\phi & =\frac{28-168}{\sqrt{(12)(28)(15)(25)}} \\
\phi & =\frac{-140}{\sqrt{126.000}} \\
& =-0,39
\end{aligned}
$$

Tabel 8. Tabel Phi Pengendara Kendaraan Bermotor Roda Dua yang Memakai Helm Standard dan Tidak Standar yang Mengalami Kecelakaan Lalu Lintas Bulan November - Desember

\begin{tabular}{lccc}
\hline Penggunaan Helm & $\begin{array}{c}\text { Tanpa } \\
\text { fraktur }\end{array}$ & $\begin{array}{c}\text { Dengan } \\
\text { Fraktur }\end{array}$ & Jumlah \\
\hline Helm Standar & 4 & 8 & 12 \\
Helm tdk standar & 8 & 4 & 112 \\
\hline
\end{tabular}

Sumber: Data Primer

$$
\begin{aligned}
\phi & =\frac{\mathrm{BC}-\mathrm{AD}}{\sqrt{(\mathrm{A}+\mathrm{B})(\mathrm{C}+\mathrm{D})(\mathrm{A}+\mathrm{C})(\mathrm{B}+\mathrm{D})}} \\
\phi & =\frac{28-168}{\sqrt{(12)(12)(12)(12)}} \\
& =-0,22
\end{aligned}
$$

\section{Pembahasan}

Dari Tabel 1 menunjukan responden dengan fraktur tulang muka dan tulang kepala berdasarkan tingkat pendidikan paling banyak didominasi oleh pelajar SMU yaitu 27 atau51,72\%, Menurut wakapolres Sleman dikarenakan emaosi yang belum stabil sehingga mereka mengendarai sepeda motor kurang perhitungan. Mereka mengendarai sepeda motor lebih sekedar karena mencari jati diri sehingga faktor keselamatan kurang diperhitungkan. Dari faktor pekerjaan responden yang mengalami fraktur tulang muka dan tulang kepala dengan mengendarai sepeda motor roda dua yaitu tani 9 orang atau $17,30 \%$, PNS 25 atau $48,84 \%$,wiraswasta 18 atau $34,61 \%$. Dari faktor umur pada Tabel 1 menunjukan bahwa umur yang lebih tua dengan yang lebih muda tidak ada perbedaan dalam menggunakan helm standar. Umur tidak mempengaruhi atau menentukan bagaimana penggunaan helm standar dengan kejadian fraktur tulang muka dan tulang kepala. Pada Tabel 6 menunjukan bahwa pengendara kendaraan bermotor roda dua yang memakai helm mengalami kecelakaan besarnya nilai signifikan $(p)$ yang besarnya $-0,036$ dimana nilai tersebut lebih kecil dari $\alpha=0,05(p<0,05)$ maka Ho ditolak,sehingga dapat dikatakan ada hubungan antara kendaraan bermotor roda dua yang memakai helm dan tidak memakai helm yang mengalami kecelakaan lalu lintas. Berdasarkan Tabel 7 pengendara kendaraan bermotor roda dua yang memakai helm standard an tidak memakai helm standar yang mengalami kecelakaan lalu lintas menunjukan berdasarkan besarnya nilai signifikan (p) yang besarnya $-0,39$, dimana nilai tersebut lebih kecil dari $\alpha=0,05(p<0,05)$ maka Ho ditolak, sehingga dapat dikatakan ada hubungan antara pengendara kendaraan bermotor roda dua yang memakai helm standar dan tidak memakai helm standar yang mengalami kecelakaan lalu lintas.

Berdasarkan tabel 8 pengendara kendaraan bermotor roda dua yang memakai helm standard dan tidak memakai helm satndar yang mengalami kecelakaan lalu lintas menunjukan besarnya nilai signifikan $(p)$ yang besarnya $-0,22$ diman nilai tersebut lebih kecil dari $\alpha=0,05(p<0,05)$ maka Ho ditolak sehingga dapat dikatakan ada hubungan antara kendaraan bermotor roda dua yang memakai 
helm dan tidak memakai helm yang mengalami kecelakaan lalu lintas. Dengan kata lain resiko terjadinya kecelakaan yang mengakibatkan fraktur tulang muka dan kepala dipengaruhi oleh jenis pemakaian helm. Maka secara teori menurut menteri Perhubungan nomor 72 tahun 1993, helm standar memiliki kunci yang lebih besar dalam mellindungi kepala disbanding dengan jenis helm lain yang tidak standar. Data yang diambil penulis juga membuktikan bahwa menggunakan helm standar dalam mengendarai kendaraan bermotor roda dua memiliki resiko fraktur tulang muka dan tulang kepala yang lebih kecil dibanding kecelakaan pada pengguna helm tidak standar apalagi pengendara kendaraan bermotor roda dua yang tidak menggunakan helm.

\section{SIMPULAN DAN SARAN}

a. Ada hubungan antara penggunaan helm standar dengan insidensi fraktur tulang muka dan fraktur tulang kepala.

b. Helm standar terbukti mengurangi resiko fraktur tulang muka dan tulang kepala pada kecelakaan kendaraan bermotor roda dua terbukti dari 12 kasus kecelakaan untuk pengguna helm standar $66,66 \%$ tidak mengalami fraktur tulang muka dan tulan kepala, sedangkan prosentase fraktur tulang muka dan tulang kepala adalah 33,33\%. Angka perbandingan lebih kecil pada kecelakaan yang disertai fraktur tulang muka dan fraktur tulang kepala dibanding kecelakaan yang tidak disertai fraktur tulang muka dan tulang kepala.

c. Pengendara tanpa helm sangat beresiko terkena fraktur tulang muka dan tulang kepala bila terjadi kecelakaan, sebab tidak ada pelindung apapun dikepala. Apabila terjadi kecelakaan dan kepala terbentur benda keras maka resiko terjadi fraktur tulang muka dan tulang kepala sangat besar. Terbukti dengan hasil penelitian 12 kecelakaan kasus kendaraan bermotor roda dua tanpa helm $75,0 \%$ mengalami fraktur tulang muka dan tulang kepala ,sedang $25,0 \%$ tidak mengalami fraktur tulang muka dan tulang kepala maka resiko terjadi fraktur tulang muka dan tulang kepala lebih besar disbanding yang tidak mengalami fraktur tulang muka dan tulang kepala.

\section{RUJUKAN}

1. Nangoy, H., Tojo, P., 2000, Jumlah Kasus Kecelakaan Lalu - lintas Periode 1975-1982, Bag. IKK FKUP/RSHS, Bandung.

2. Bangks,Peter ,1992, Fraktur Pada Mandibula ,Ed.3 1-9, Gajah Mada University Press,Yogyakarta.

3. Elisabeth j Corwin,2002, Alih bahasa Endah P, Patofisiologi Klinik, EGC Jakarta.

4. Mulyadi J Amalik, relawan pada Pusat Studi Hak Asasi Manusia (PUSHAM), UII Yogyakarta).

5. Pusat Studi Hukum (PSH),2006, Analisis Kegunaan Helm Standar Oleh Pengendara Kendaraan Roda Dua Di Yogyakarta,UII,Yogyakarta.

6. Krunger, G.O, 2000, oral and maxillofacial Surgery, Ed, 364-416,TheC.V.Mosboy, St.Louis, Toronto

7. Armys, Trauma Sistema Muskuloskeletal,1995 Fakultas Kedokteran UGM Yogyakarta.

8. UU no 14 tahun 1992 tentang lalu lintas, Keputusan menteri Perhubungan no 72 tahun 1993.

9. Riwidikdo, H. (2006). Statistik Kesehatan:Belajar Mudah Teknik Analisa Data Dalam Penelitian Kesehatan. Jogjakarta: MITRA CENDEKIA Press. 